\title{
Cleidocranial dysplasia: a case report of a rare anomaly
}

\author{
Kumar $V V,^{1^{*}}$ Nithyanand $S,{ }^{2}$ Kumar $V^{1}$ \\ ${ }^{1}$ Department of Anatomy, K.S. Hegde Medical Academy, Nitte University, Mangalore, India, ${ }^{2}$ Department of \\ Radiodiagnosis, Vikran Hospital, Mysore, India
}

\begin{abstract}
*Corresponding Author:
Dr.Vinay Kumar. V.

Assistant Professor, Department of Anatomy, K.S. Hegde Medical Academy,

Deralakatte, Mangalore-575018, India,

Email: drvinay66475@rediffmail.com
\end{abstract}

\section{Citation}

Kumar VV, Nithyanand S, Kumar V. Cleidocranial dysplasia: a case report of a rare anomaly. Nepal Journal of Medical sciences 2012;1(2):135-7.

\begin{abstract}
Cleidocranial dysplasia (CCD) is a rare hereditary disease of unknown etiology which was previously known as cleidocranial dysotosis. It usually follows an autosomal dominant mode of transmission. The phenotype is characterized by general dysplastic bone formation manifested by abnormalities in the shoulder girdle, skull, jaw and dentition. We report a case of a six year old female child presenting with classical features of CCD. An outstanding feature of this case is that it did not follow a familial pattern of inheritance since the patient is the only member in the family suffering from such disorder. The clinician should be aware of the characteristic features of $\mathrm{CCD}$ for early diagnosis and initiating the appropriate treatment. The clinical, radiological findings and its embryological cause are discussed.
\end{abstract}

Keywords: Autosomal dominant; cleidocranial dysplasia; dysostosis

\section{Introduction:}

$\mathrm{C}$ leidocranial dysplasia (CCD), also known as Marie and Saiton disease, Scheuthauer- Marie-Sainton syndrome, Mutational dysostosis ${ }^{1}$ is a rare disease with autosomal dominant inheritance characterized by clavicular aplasia or hypoplasia, retarded cranial ossification, supernumerary teeth, short stature and a variety of other skeletal abnormalities. ${ }^{2}$ This condition is of clinical significance to the dentist due to involvement of facial bones, altered eruption patterns and presence of multiple supernumerary teeth. ${ }^{3}$ CCD was first described by Pierre Marie and Paul Sainton in $1894 .^{4}$ The pathognomonic features for diagnosis of CCD are multiple supernumerary teeth, partial or complete absence of clavicle and open fontanelle. ${ }^{5}$

Most documented cases of CCD are caused by mutations in the transcription factor RUNX2 gene, located at chromosome $6 \mathrm{p} 21$. This gene encodes a protein necessary for the correct functioning of osteoblast cells. However $40 \%$ of cases of CCD appear spontaneously with no apparent genetic cause. It affects most prominently those bones derived from endochondral and intramembranous ossification such as the cranium and the clavicles. ${ }^{6}$ It is a relatively uncommon disorder with a prevalence of 0.5 per 100000 live births. ${ }^{5}$ The rarity of this disease prompted us to report this case.

\section{Case report:}

A 6 year old female patient presented in the outpatient department complaining of unclosed anterior fontanelle. On physical examination the anterior fontanelle was open. She was noted to have bilateral absence of clavicles, supernumerary teeth, frontal bossing, hypertelorism and short metacarpal bones. The patient was able to approximate the shoulders anteriorly (Figure 1A). 

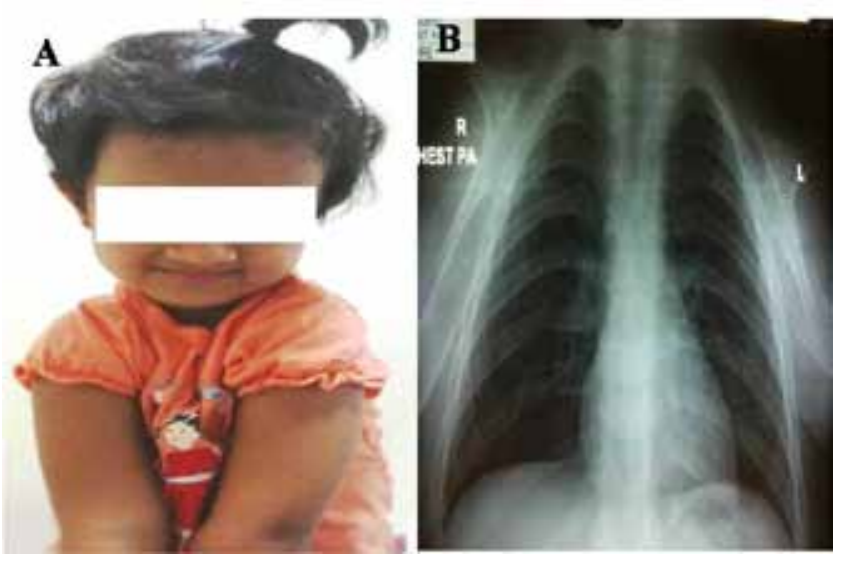

Figure 1A: Photograph of 6 yr old child showing the anterior apposition of shoulders due to absence of clavicles. Fig 1B: Radiographic film of the same child showing bilateral complete absence of clavicle.

Other systemic examinations were normal. No other member of her family had bony abnormalities, delayed ossification or short stature.

Laboratory investigations showed normal serum calcium, phosphorus, alkaline phosphatase, parathyroid hormone and vitamin D levels. Thyroid function tests were within normal ranges. Chest $\mathrm{x}$ - ray revealed absence of clavicle on both sides (Figure 1B). Skull x-rays showed presence of wormian bones, open anterior fontanelle (Figure 2A), existence of several dental elements retained and impacted in maxilla and mandible (Figure 2B).

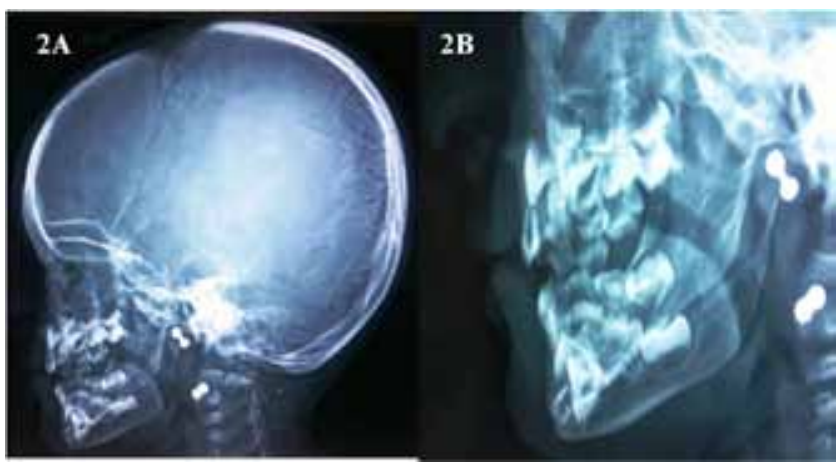

Fig 2: Plain X-ray lateral views of skull showing open anterior fontanella (A) and multiple supernumerary teeth (B).

The maxillary air sinus was underdeveloped (Figure 2B). Antero-posterior and lateral $\mathrm{x}$-rays of spine showed wide inter pedicular distance (Figures 3A and 3B). X-ray of wrist showed only 3 carpal bones and short metacarpal bones (Figures 3C and 3D). Based on these clinical and radiological findings, the patient was diagnosed as a case of CCD.

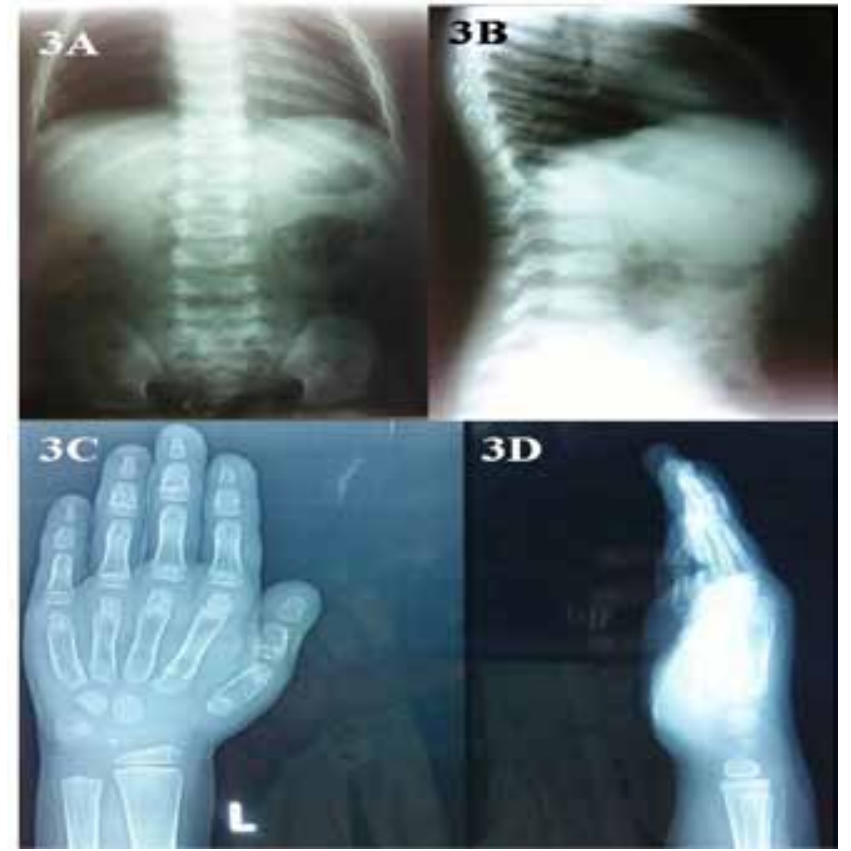

Fig 3A and 3B: Antero-posterior and lateral view of spine showing wide inter-pedicular distance. Fig $3 \mathrm{C}$ and 3D: Antero-posterior and lateral $x$-ray of hand and wrist showing short metacarpals and presence of 3 carpal bones.

\section{Discussion:}

A familial incidence was recorded in approximately $2 / 3 \mathrm{rd}$ of the reported cases of CCD and the condition was found in as many as five successive generations. When inherited, it appears as an autosomal dominant disease. ${ }^{7}$ In those cases which appeared to have developed sporadically, as with the case presented here, it has been suggested that they represent a recessively inherited disease or more likely either an incomplete penetrance in a genetic trait with variable gene expression or a true new dominant mutation. ${ }^{8}$ In our case, the patient did not report the existence of direct ancestors or descendents who presented any clinical characteristic of CCD.

This case discusses several characteristic anomalies in a patient with CCD. Individuals with this disorder present with characteristic features like large brachycephalic head, small and angular face, prominent frontal and parietal bones and drooping shoulder with excessive mobility. Depending on the amount of clavicular involvement, the patient may be able to approximate the shoulders anteriorly. ${ }^{5}$ High arched palate, retention of deciduous teeth, delayed eruption of permanent teeth and the presence of large number of impacted supernumerary teeth are all classical oral findings in CCD. ${ }^{9}$

There is a generalized failure of midline ossification resulting 
in patent fontanella, metopic suture, wormian bones, nasal deformity, non-union of mandibular symphysis, high arched palate, cleft palate, hypoplasia or absence of clavicles, spina bifida and delayed closure of pubic symphysis. ${ }^{10}$ Most of these features were seen in the present case. Final height is significantly reduced in patients with CCD.

Previous investigations indicate that the birth height is normal but the height drops below or around the $2^{\text {nd }}$ centile between the ages of 4 and $8 .{ }^{11,12}$ This is concordant with our patient. Patients usually have mild disproportionate short stature with short limbs compared to trunk, more apparent in upper limbs than in lower limbs. Female patients are more affected than male patients. ${ }^{13}$ Other skeletal abnormalities include delayed mineralization of pubic bone, wide symphysis pubis, narrow pelvis and spondylolysis. There may be syringomyelia or spina bifida occulta. ${ }^{14}$ The thoracic cage is small and bell shaped with short ribs. ${ }^{15}$

Common complications of CCD include pes planus, genu valgum, shoulder and hip dislocation, recurrent sinusitis, upper airway complications, recurrent ear infection, hearing loss, dental caries, osteomyelitis of the mandible or maxilla, respiratory distress in early infancy etc. ${ }^{16-18}$ Even with these complications the life span in such patients is normal. None of the above mentioned complications were found in the present case.

\section{Conclusion:}

CCD is very rarely encountered in clinical practice and is generally diagnosed incidentally. Most important and reliable tool to confirm the diagnosis is radiographic evaluation of the patient. The clinician should be aware of the characteristic features of CCD for early diagnosis and initiating the appropriate treatment approach. It should be considered in the differential diagnosis of short stature with skeletal abnormalities like large fontanella and wormian bones. Early diagnosis allows a proper orientation for the treatment, offering a better compliance to the patient and with anticipatory guidance, people with CCD lead healthy and productive life.

\section{References:}

1. Shafer WG, Hine MK, Levy BM, et al. A textbook of Oral Pathology. 4th Ed. Philadelphia. Saunders 2000:678-80.

2. Björn H, Grahnén H. Cleido-cranial dysostosis. Odontol Revy 1966;17:167-75.

3. Kalliala E, Taskinen PJ. Cleidocranial dysostosis.
Report of six typical and one atypical case. Oral Surg Oral Med Oral Pathol 1962;15:808-22.

4. Marie R, Sainton R. Sur la dysostose cleido-cranienne hereditaire. Rev Neur 1898;6:835-8.

5. Mundlos S. Cleidocranial dysplasia: clinical and molecular genetics. J Med Genet 1999;36:177-82.

6. Zhou G, Chen Y, Zhou L, et al. CBFA1 mutation analysis and functional correlation with phenotypic variability in cleidocranial dysplasia. Hum Mol Genet 1999;8:2311-6.

7. Aegert E, Kirkpatrik JA. The skeletal dysplasia. Orthopedic Diseases, 4th Ed., Philadelphia.WB Saunders Co 1975:193-5.

8. Forland M. Cleidocranial dysostosis. A review of the syndrome and report of a sporadic case, with hereditary transmission. Am J Med 1962;33:792-9.

9. Shafer WG, Hine MK, Levy BM. Diseases of Bones and Joints; Cleidocranial Dysplasia. Oral Pathology. 4th Ed.Philadelphia. WB Saunders Co 1984:363-5.

10. Jensen BL. Somatic development in Cleidocranial dysplasia. Am J Med Genet 1990;35:69-74.

11. Kempfle B. Familial Cleidocranial dysostosis. Dtsch Zahnartl Z 1965;20:1364-9.

12. Levin EJ, Sonnenschein H. Cleidocranial dysostosis. N Y State J Med 1963;63:1562-6.

13. Jensen BL. Somatic development in cleidocranial dysplasia. Am J Med Genet 1990;35:69-74.

14. Gulati S, Kabra M. Cleidocranial dysplasia. J Postgrad Med 2001;47:204-5.

15. Mendoza LR, Lee B. Cleidocranial dysplasia In: Pagon RA, Bird TD, Dolan CR, Stephens K, ed. GeneReviews [Internet]. University of Washington. Seattle. [updated 2009 Jun 25].

16. Golan I, Baumert U, Hrala BP, et al. Dentomaxillofacial variability of cleidocranial dysplasia: clinicoradiological presentation and systematic review. Dento maxillofac Radiol 2003;32:347-54.

17. Yochum TR, Rowe LJ. Essentials of Skeletal Radiology. 2nd Ed. Baltimore. Williams and Wilkins 1996;589-92.

18. Cooper SC, Flaitz CM, Johnston DA, et al. A natural history of cleidocranial dysplasia. Am J Med Genet 2001;104:1-6. 